\title{
Brazilian Abstracts Presented at the American Urological Association Annual Meetings: Contribution, Publication Rates, and Comparison with Oncology Abstracts
}

\author{
Marco A. Arap ${ }^{1,3}$, Rodolfo Borges dos Reis², Fábio César Miranda Torricelli ${ }^{3}$, André L. S. Masson ${ }^{4}$, \\ Everardo D. Saad ${ }^{4}$ \\ ${ }^{1}$ Hospital Sírio-Libanês, São Paulo, ${ }^{2}$ Faculdade de Medicina de Ribeirão Preto da Universidade de São \\ Paulo, Ribeirão Preto, ${ }^{3}$ Faculdade de Medicina da Universidade de São Paulo, São Paulo, ${ }^{4}$ Dendrix \\ Research, São Paulo, Brazil
}

\section{ABSTRACT}

Purpose: Scientific research originating from Brazil appears to be rising in several medical fields. Research results are often presented at scientific meetings before publication in peer-reviewed journals. We investigated the publication rate of Brazilian studies presented in American Urological Association (AUA) meetings and compared with the rate of publication of Brazilian oncological studies presented at the American Society of Clinical Oncology (ASCO) meetings.

Materials and Methods: a hand search of 12,454 abstracts presented at aua meetings 2001-2007 was conducted. abstracts for which at least two-thirds of institutions were from brazil were considered as brazilian. final publication was searched in pubmed and lilacs databases. oncological abstracts were also hand searched in the asco meetings proceedings in the same years.

Results: There was no significant temporal trend in the proportion of AUA studies originating from Brazil along those 7 years. A total of 195 abstracts (1.57\%) were from Brazil. One hundred (51.3\%) abstracts were published in full, and the estimated 5-year publication rate was $48.2 \%$. There was a progressive increase in publication rates for studies categorized as video, poster, and podium presentations. Considering abstracts presented in years 2001-2005, urologic publication rate was significantly higher than for abstracts presented at the ASCO meeting.

Conclusions: Our results suggest that the Brazilian contribution to AUA meetings is at a plateau and that the Brazilian literature contribution is greater in urology than in oncology. Efforts must be invested towards raising this plateau and understanding qualitative aspects of the urology scientific output from Brazil.

\section{ARTICLE INFO}

\section{Key words:}

Bibliometrics; Brazil; meeting abstracts; neoplasms; research design; urology

Int Braz J Urol. 2014; 40: 730-7

Submitted for publication: December 05, 2013

Accepted after revision:

May 03, 2014

\section{INTRODUCTION}

The presentation of abstracts at scientific meetings, often before attempts at publication in peer-reviewed journals, is an integral component of medical research. However, many studies pre- sented in abstract form are never published in full $(1,2)$. The American Urological Association (AUA) Annual Meeting is considered the premier source from which urology professionals from all over the world can learn about the latest advances in this field (3). Previous authors have investigated 
the fate of abstracts presented at the AUA Annual Meetings (4-8). Likewise, work has been done to assess the fate of Brazilian studies presented as abstracts in the 2003 meeting of the Brazilian Society of Urology (9). To our knowledge, however, there have been no previous studies on Brazilian abstracts presented at AUA Annual Meetings. We and others have shown an increasing Brazilian contribution in the areas of cardiology, neurology, oncology, and psychiatry, among others (10-13). In the current study, we attempted to quantify the scientific output from Brazil in recent editions of the AUA Meetings. As a secondary goal, we aimed to compare the urological scientific output with the experience described previously in oncology, which has shown that the Brazilian contribution in this field is quantitatively increasing in a statistically significant fashion, albeit with low publication rates (13).

\section{MATERIALS AND METHODS}

\section{Selection of abstracts}

The selection of abstracts was done following the same method used in a prior study in oncology, in which Brazilian abstracts accepted for the Annual Meetings of the American Society of Clinical Oncology (ASCO) were analyzed (13). Briefly, a hand search of the Program Proceedings of the AUA Annual Meetings for the years 2001 through 2007 was conducted. Studies accepted by the program committee of the AUA Annual Meetings may be presented in several forms, including podium (oral), poster, and video presentations. Despite the fact that poster presentations received varying denominations along the years comprised in the study period, all such denominations were grouped under the same category for the current analysis. During the search, an attempt was made to identify all Brazilian studies, which were defined as those for which at least two-thirds of institutions were from Brazil (i.e., multinational studies which included Brazilian investigators were not analyzed unless the aforementioned criterion was met). Studies described in the abstracts were categorized, on the basis of their profile, as predominantly basic-science, cli- nical, or epidemiological research. Importantly, no attempt was made to appraise the results or scientific merit of the studies.

\section{Search for full papers}

For each abstract included in the analysis, PubMed and Lilacs databases were used with the goal of locating its full publication. The search strategy consisted of using the last names of the first or last authors for each abstract, in addition to one or more keywords related to the subject of interest $(13,14)$. Date of publication was the date of the journal issue, when available, or the 15th day of the month of publication otherwise. For full publications that originated from abstracts presented in more than one AUA Meeting, only the abstract first presented was considered as published, whereas subsequent AUA presentations of the same study were considered as non-published.

\section{Statistical analysis}

Proportions were calculated, with corresponding 95\% confidence intervals (CI) when appropriate. The variation in the proportion of Brazilian studies along the years was assessed using the chi-square test for trend. The time to full publication of the abstracts was estimated using the Kaplan-Meier method. Although we had publication data for urology abstracts for the whole study period (2001 through 2007), a comparison was undertaken between the publication rates of the urology abstracts for years 2001 through 2005 and the oncology abstracts for these same years described elsewhere, since we had no data for oncology abstracts for the years 2006 and 2007 (13). However, the search for full publications of the oncology abstracts was updated for the present study, in order to provide the same median follow-up times-as measured from each annual meeting analyzed-for both specialties (these two annual meetings usually take place only one month apart). The curves of time to publication were compared between types of urology abstract, as well as between urology and oncology abstracts, using the log rank test. All reported $\mathrm{P}$ 
values are two-sided, and statistical significance was considered if $\mathrm{P}<0.05$. The software used was MedCalc (Mariakerke, Belgium).

\section{RESULTS}

Number and features of Brazilian studies

A total of 12,454 abstracts published in the AUA Program Proceedings were screened. Of this total, 195 were Brazilian studies, for an annual average of $27.9 \pm 9.3$ abstracts. Therefore, Brazilian studies represented $1.57 \%$ of all studies presented at the AUA Meetings analyzed (95\% CI, 1.36\%-1.80\%). Among the 195 Brazilian studies, 163 (83.6\%) were categorized as clinical investigation, $25(12.8 \%)$ as basic research, and seven (3.6\%) as epidemiologic research. Brazilian states with the highest number of abstracts from a single state were São Paulo $(\mathrm{N}=148)$, Rio de Janeiro $(\mathrm{N}=21)$ and Rio Grande do Sul $(\mathrm{N}=16)$; the remaining 10 abstracts were from other states $(\mathrm{N}=5)$ or from more than one state. No support from financial sources were declared in 189 abstracts; for the remaining six, pharmaceutical industry was declared as a source of support in three studies, and government or private grants were acknowledged in three cases.

Temporal trends in Brazilian urology studies

Figure-1 displays the number of Brazilian studies accepted by the program committee of the AUA Meeting between 2001 and 2007. There was no significant trend in the proportion of Brazilian studies along the 7 years comprised in the study period, in relation to the overall number of abstracts accepted each year $(\mathrm{P}=0.743)$.

Publication of urology abstracts

The publication rate of urology abstracts for the period 2001 through 2007 is shown in Figure-2. Four studies giving rise to full publications were presented in more than one AUA Meeting (thus, only the first abstract was considered as published in each of these four cases). Of 195 abstracts analyzed, 100 (51.3\%; 95\% CI, $44.1 \%$ to $58.5 \%$ ) were published in full. The Kaplan-Meier estimate for publication rate at 5

Figure 1 - Absolute numbers (shown inside the graph) and percentages (Y-axis) of Brazilian studies presented at the American Urological Association in years 2001 through 2007 ( $P$ for trend=0.743).

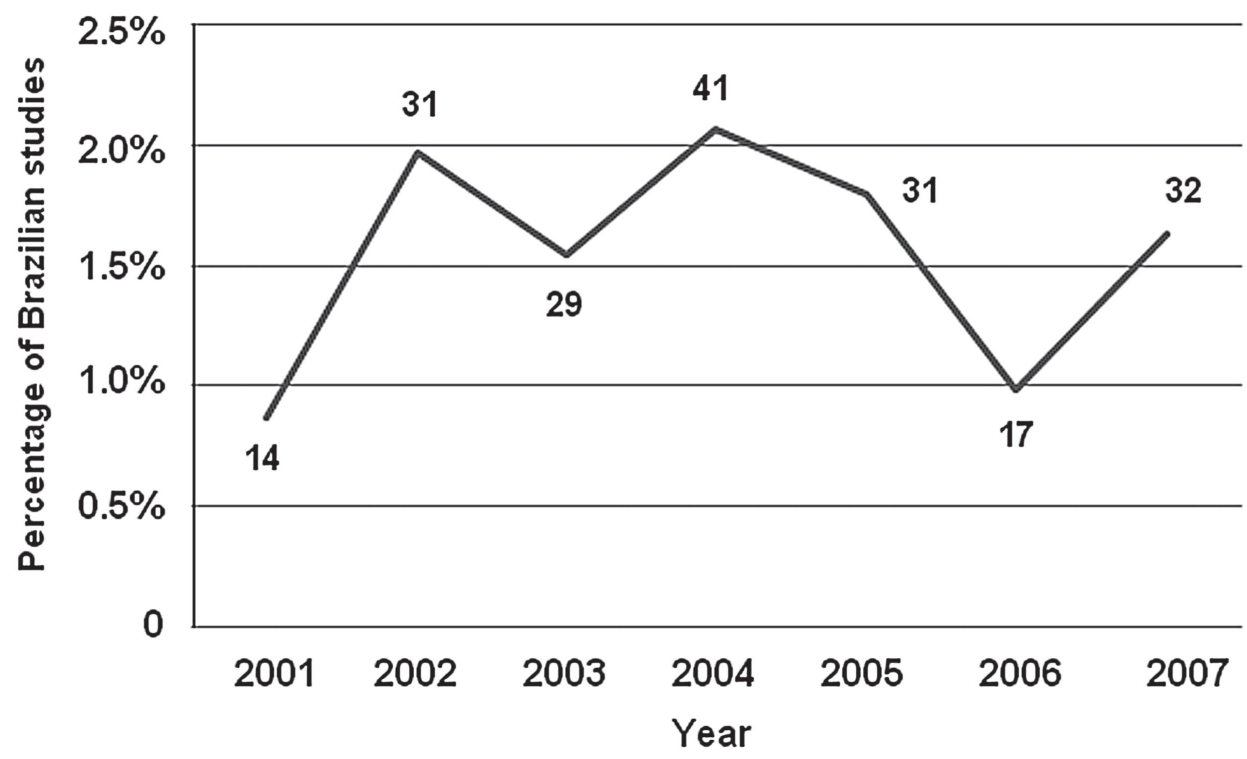


Figure 2 - Time to full publication of Brazilian studies presented at the American Urological Association Annual Meetings between 2001 and 2007 (tick marks represent censoring).

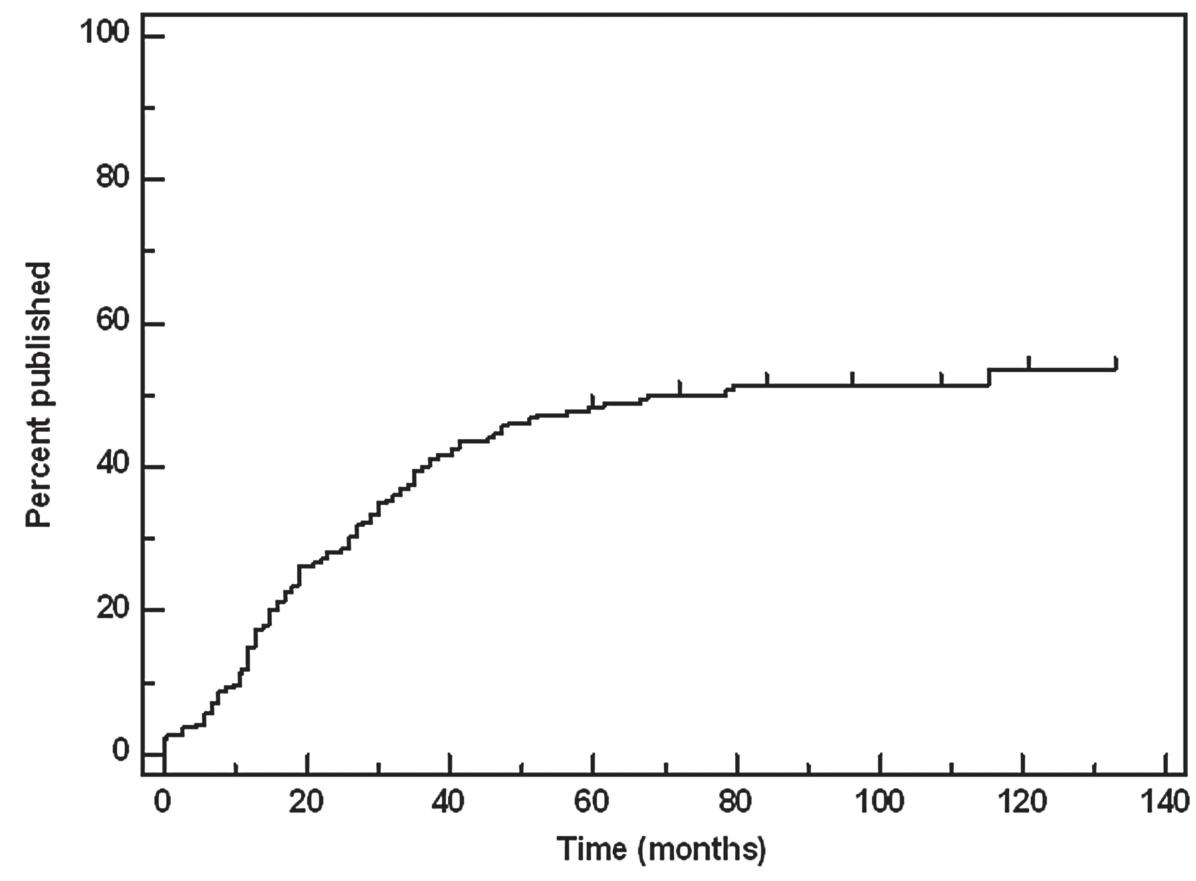

years was 48.2\%. Four abstracts were published in full before the date of the corresponding AUA Meeting (with a range of 2.5 to 7.6 months); for these papers, we considered the time to publication as zero, in order to avoid negative times. When only published papers were considered, the median time to publication was 18.8 months. Of the 100 published studies, 55 appeared in print within 2 years from presentation of the abstract. The publication rates for each of the 7 year comprised in the study period were 50\%, 51.6\%, 41.4\%, 56.1\%, 41.9\%, $52.9 \%$, and $46.9 \%$, respectively (P for trend $=0.840$ ). As shown in Figure-3, there were statistically significant differences in publication rates among urologic studies categorized as podium, poster and video presentations $(\mathrm{P}=0.006$ for the comparison among the three categories).

Comparison between urology and oncology abstracts In comparison with the rate of contribution from Brazil in the field of oncology (i.e., to the ASCO Meetings 2001 through 2007), there was a significantly higher rate of Brazilian contribution to the AUA Meetings 2001 through 2007 (Table-1). With regard to publication rates, Figure- 4 shows that the 146 urology abstracts (2001 through 2005) were more likely than the 154 oncology abstracts (2001 through 2005) to be published in full. The hazard ratio for this comparison is 1.51 (95\% CI, 1.07 to 2.12 ), indicating that urology abstracts have a nearly 50\% higher chance of being published $(\mathrm{P}=0.019)$.

\section{DISCUSSION}

The current analysis suggests that the Brazilian scientific output in urology is at a plateau in relation to the AUA Meeting. On the other hand, the study also suggests that the publication rate of such studies in indexed journals is not trivial, and that the urology contribution is higher than that of oncology. Our results may be put in perspective by comparing them with those from similar assessments conducted in urology and in other fields. Oliveira et al. found that 39\% of the abstracts presented in oral fashion at the 
Figure 3 - Time to full publication of Brazilian studies, according to category of presentation at the American Urological Association Annual Meetings 2001 through 2007 (tick marks represent censoring).

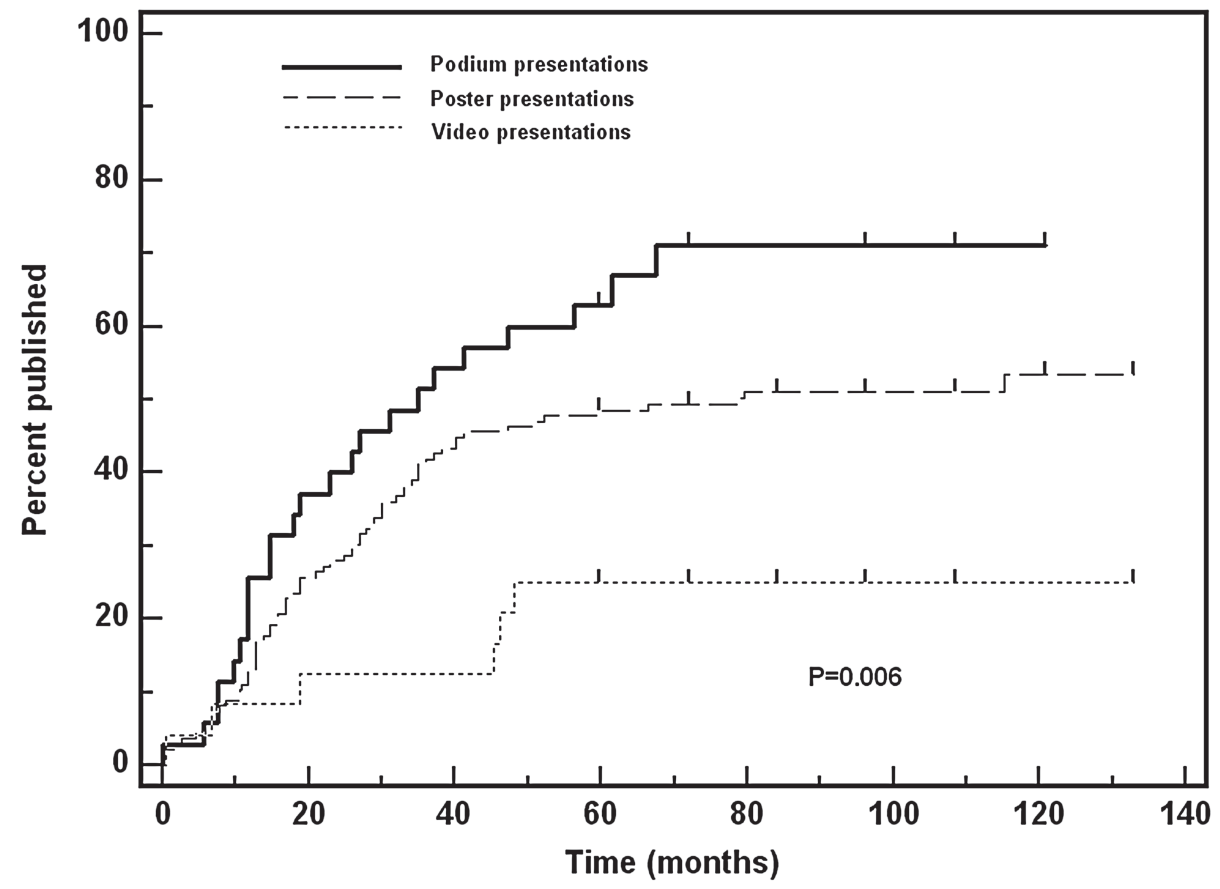

Table 1 - Comparison of contribution rates from Brazilian studies presented at the American Urological Association and American Society of Clinical Oncology Annual Meetings 2001 through 2007 (data for oncology are from Pinheiro et al. ${ }^{22}$ ).

\begin{tabular}{lcc}
\hline Annual Meeting & Proportion of Brazilian Abstracts & P value \\
\hline American Urological Association & $1.57 \%(195$ of 12,454$)$ \\
American Society of Clinical Oncology & $0.97 \%(244$ of 24,998$)$ \\
\hline
\end{tabular}

Brazilian Society of Urology meeting 2003 were published (9). Regardless of presentation type, overall publication rates ranging from $37.8 \%$ to $55 \%$ were reported in studies that assessed AUA Meetings, $(4,5,8)$ whereas Fesperman et al. found a rate of 33.5\% when the Southeastern Section of AUA was considered (6). Likewise, Autorino et al. reported a publication rate of $47.3 \%$ for abstracts presented at the European Association of Urology Meetings 2000-2001 (15), whereas Rao et al. found a rate of $42 \%$ for abstracts presented at the annual meetings of the British Association of Urological Surgeons (16). On the other hand, a rate of only 29.8\% was found for abstracts presented at annual meetings of the Urological Society of Australia and New Zealand (17). The fate of abstracts presented at scientific meetings has been analyzed in several other fields. In a landmark study, Goldman and Loscalzo described the fate of cardiology abstracts presented at three meetings, and found that $49.6 \%$ of them were published in peer-reviewed journals (18). In another study evaluating abstracts presented at the ASCO Meeting, De Bellefeuille et al. found that $58 \%$ of abstracts led to full papers (14). Publication rates have also been reported in radiology (35\%) (19), 
Figure 4 - Time to full publication of Brazilian studies presented the American Urological Association and American Society of Clinical Oncology Annual Meetings 2001 through 2005 (data for oncology were updated from Saad et al. ${ }^{13}$; tick marks represent censoring).

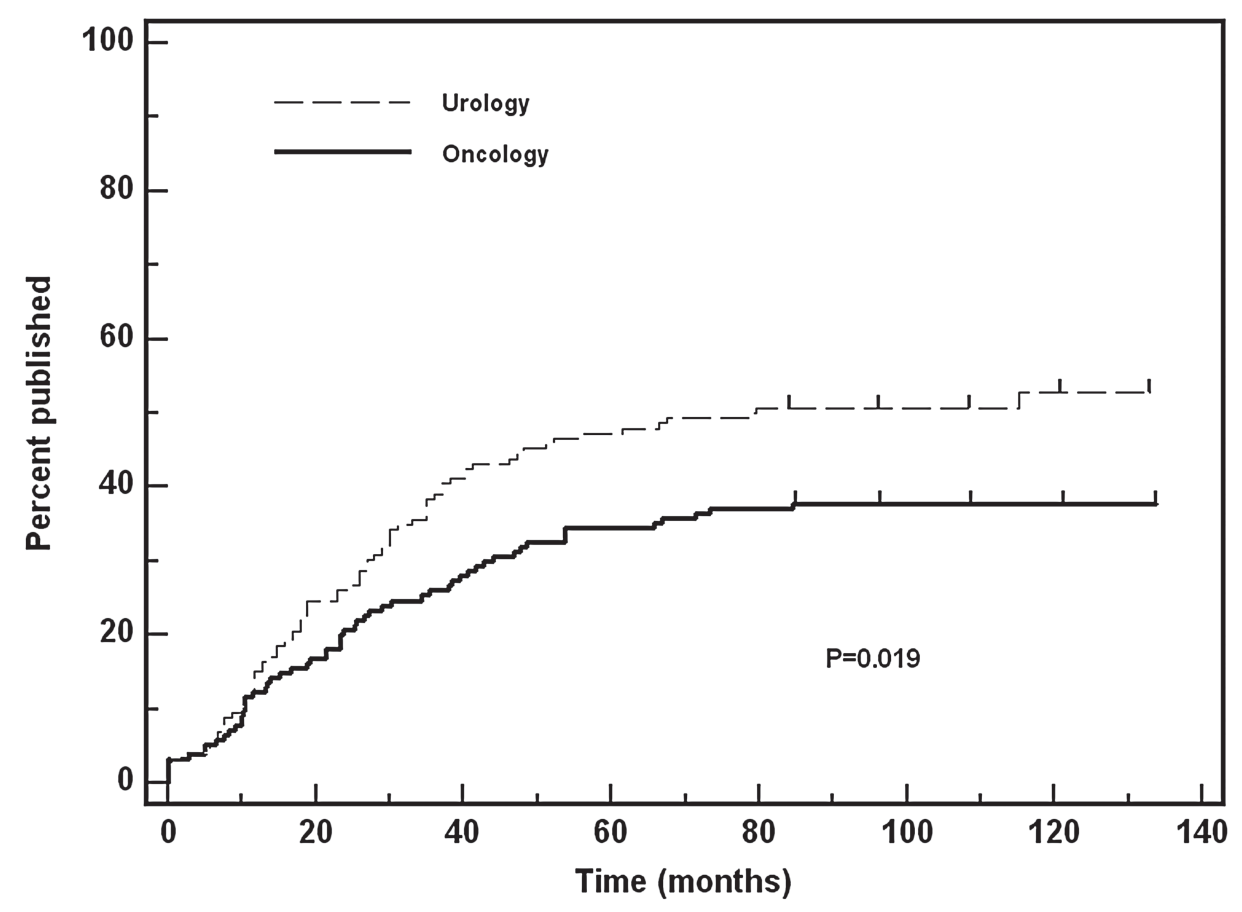

in orthopedics (34\%) (20), and in plastic surgery (45\%) (21), among other fields. A meta-analysis of 79 reports that examined the publication rates of studies initially presented as abstracts showed that $44.5 \%$ of these studies get published (2). Thus, the publication rate found for Brazilian urology abstracts in our study is on the high end of publication rates reported worldwide and in different medical fields. Of note, the graded increase in publication rates according to type of presentation observed in the current study was also noted by Hoag et al. (8), but not by Rao et al. (16). Podium presentations are more prone to be published, probably reflecting a better quality of such studies.

The fact that our methodology was used previously in oncology (13) allowed for a comparison between these two areas in the same period of time (2001-2005), showing that urology abstracts are more prone to be published (51.4\%) than oncology abstracts (37.7\%). Although we believe this comparison between the output of urology researchers and oncology researchers from Brazil is adequate, as it involves the same years and meetings of equivalent magnitude within their corresponding fields, we should point out that this is an univariate comparison, as we could not adjust for confounders, such as type of presentation and type of the research. With regard to the former, the differences between the two meetings preclude proper adjustment; as for the latter, we did not appraise the contents of abstracts or its quality. It is possible that these or other important determinants of publication rates differ between the groups compared.

In addition to the comparison of publication rates, our study allows for the comparison between urology and oncology in terms of their relative contribution to their corresponding scientific meetings (Table-1). Although the period analyzed was relatively short, the data suggest that the contribution rates in urology fluctuated around an annual stable average, whereas for oncology there was an upward trend $(13,22)$. 
We may speculate that the stability of contribution rates in urology is a sign of greater scientific maturity of this specialty in Brazil, with opposing interpretation in the case of oncology, a newer specialty. On the other hand, such scientific maturity hovers around a plateau that may or may not be considered as adequate in terms of what Brazilian urology researchers would like to see for their specialty. Unfortunately, we have not been able to quantify the contribution of other countries to AUA Meetings, as done by our group in the case of oncology (23). It is important to stress out the reasons why we searched the AUA Meetings from 2001 through 2007; such years were chosen with the aim of allowing a relatively long follow-up since the original presentation of abstracts. This action prevented that time would be a limitation for the abstracts to be written and published.

We believe this type of study is important for the Brazilian scientific community, as it allows for a quantitative assessment of the relative contribution from Brazilian investigators to the international scenario. However, our study has some limitations. First, we only looked at studies presented at the AUA Meeting. Although considered by many as the most important scientific event in urology, this meeting is one of many international events at which Brazilian investigators might present the results of their studies. Thus, it is possible that the analysis of other meetings would show different rates of Brazilian investigators' contribution. A second limitation stems from the fact that we assessed the proportional Brazilian contribution in the form of abstracts. It is conceivable that good-quality Brazilian research during the 7 years analyzed was submitted for full publication without prior presentation at the AUA Meeting. Such possibility would lead to an underestimation of the Brazilian productivity, as long as researchers from the rest of the world behaved in a different manner, i.e., had a higher trend than Brazilian investigators to present their results as abstracts before attempting full publication. A third limitation of this type of analysis is that it does not allow for an assessment of a differential rate of acceptance of Brazilian studies by the program committee of the AUA Meeting, in comparison with studies from the rest of the world. Since the total number of studies per country sub- mitted to the meeting (i.e., the denominator of the proportion of accepted studies per country) is not known, this comparison cannot be made. A fourth limitation of our study is that we only assessed quantitative aspects of the abstracts, as their quality was not directly analyzed. We believe this type of analysis would be a bit less informative, as far as determining the contribution of Brazilian studies to the worldwide literature. In addition, we only analyzed the AUA meeting and no national meetings. Finally, some of the abstracts could be published in years that we did not evaluate, which could increase the publication rate of both groups.

\section{CONCLUSIONS}

Our study suggests that the Brazilian contribution to AUA Meetings is at a plateau. Future studies could be done in order to better understand qualitative aspects of the urology scientific output from Brazil, as well as quantitative aspects related to the published literature. Finally, our study suggests that the Brazilian contribution to the international literature is greater in urology than in oncology, both in terms of percentage of abstracts in equivalent scientific meetings and in terms of indexed publications.

\section{REFERENCES}

1. Krzyzanowska MK, Pintilie M, Tannock IF: Factors associated with failure to publish large randomized trials presented at an oncology meeting. JAMA. 2003; 290: 495-501.

2. Scherer RW, Langenberg P, von Elm E: Full publication of results initially presented in abstracts. Cochrane Database Syst Rev. 2007; MR000005

3. Nickel JC, Furuta A, Chancellor MB, Roehrborn CG, Assimos DG, Shapiro E, et al.: Best of the AUA Annual Meeting: Highlights From the 2010 American Urological Association Meeting, May 29-June 3, 2010, San Francisco, CA. Rev Urol. 2010; 12: e134-46.

4. $\mathrm{Ng} \mathrm{L}$, Hersey K, Fleshner N: Publication rate of abstracts presented at the annual meeting of the American Urological Association. BJU Int. 2004; 94: 79-81.

5. Smith WA, Cancel QV, Tseng TY, Sultan S, Vieweg J, Dahm P: Factors associated with the full publication of studies presented in abstract form at the annual meeting of the American Urological Association. J Urol. 2007; 177: 1084-8; discussion 1088-9. 
6. Fesperman SF, West CS, Bischoff CJ, Algood CB, Vieweg J, Dahm P: Study characteristics of abstracts presented at the annual meetings of the southeastern section of the American Urological Association (1996-2005). J Urol. 2008; 179: 66771; discussion 671-2.

7. Turpen RM, Fesperman SF, Smith WA, Vieweg J, Dahm $P$ : Reporting quality and information consistency of randomized, controlled trials presented as abstracts at the American Urological Association annual meetings. J Urol. 2010; 184: 249-53

8. Hoag CC, Elterman DS, Macneily AE: Abstracts presented at the American Urological Association Annual Meeting: determinants of subsequent peer reviewed publication. $J$ Urol. 2006; 176: 2624-9; discussion 2629.

9. Oliveira LR, Figueiredo AA, Choi M, Ferrarez CE, Bastos AN, Netto JM: The publication rate of abstracts presented at the 2003 urological Brazilian meeting. Clinics (Sao Paulo). 2009; 64: 345-9.

10. Rodrigues PS, Fonseca L, Chaimovich H: Mapping cancer, cardiovascular and malaria research in Brazil. Braz $\mathrm{J}$ Med Biol Res. 2000; 33: 853-67.

11. Bressan RA, Gerolin J, Mari JJ: The modest but growing Brazilian presence in psychiatric, psychobiological and mental health research: assessment of the 1998-2002 period. Braz J Med Biol Res. 2005; 38: 649-59.

12. Nitrini $R$ : The scientific production of Brazilian neurologists: 1995-2004. Arq Neuropsiquiatr. 2006; 64: 538-42.

13. Saad ED, Pinheiro CM, Masson AL, Borghesi G, Hoff PM, Prisco FE: Increasing output and low publication rate of Brazilian studies presented at the American Society of Clinical Oncology Annual Meetings. Clinics (Sao Paulo). 2008; 63: 293-6.

14. De Bellefeuille C, Morrison CA, Tannock IF: The fate of abstracts submitted to a cancer meeting: factors which influence presentation and subsequent publication. Ann Oncol. 1992; 3: 187-91.

15. Autorino R, Quarto G, Di Lorenzo G, De Sio M, Damiano $\mathrm{R}$ : Are abstracts presented at the EAU meeting followed by publication in peer-reviewed journals? A critical analysis. Eur Urol. 2007; 51: 833-40; discussion 840.
16. Rao AR, Beatty JD, Laniado M, Motiwala HG, Karim OM: Publication rate of abstracts presented at the British Association of Urological Surgeons Annual Meeting. BJU Int. 2006; 97: 306-9.

17. Yoon PD, Chalasani V, Woo HH: Conversion rates of abstracts presented at the Urological Society of Australia and New Zealand (USANZ) Annual Scientific Meeting into fulltext journal articles. BJU Int. 2012; 110: 485-9.

18. Goldman L, Loscalzo A: Fate of cardiology research originally published in abstract form. N Engl J Med. 1980; 303: 255-9.

19. Bydder SA, Joseph DJ, Spry NA: Publication rates of abstracts presented at annual scientific meetings: how does the Royal Australian and New Zealand College of Radiologists compare? Australas Radiol. 2004; 48: 25-8.

20. Bhandari M, Devereaux PJ, Guyatt GH, CookDJ, Swiontkowski MF, Sprague S, et al.: An observational study of orthopaedic abstracts and subsequent full-text publications. J Bone Joint Surg Am. 2002; 84-A: 615-21.

21. Gregory TN, Liu T, Machuk A, Arneja JS: What is the ultimate fate of presented abstracts? The conversion rates of presentations to publications over a five-year period from three North American plastic surgery meetings. Can J Plast Surg. 2012; 20: 33-6.

22. Pinheiro CMA, Masson ALS, Faingezicht AM, Borghesi G, Rotea, Jr, W, Prisco FE, et al. Estudos brasileiros apresentados nos encontros anuais da ASCO entre 2001 e 2007: aumento de produção, com baixa taxa de publicação. Rev Bras Cancerol 2009;55:221-7.

23. Saad ED, Mangabeira A, Masson AL, Prisco FE: The geography of clinical cancer research: analysis of abstracts presented at the American Society of Clinical Oncology Annual Meetings. Ann Oncol. 2010; 21: 627-32.
Correspondence address: Marco A. Arap, MD Rua D. Adma Jafet, 50 São Paulo, 01308-050, SP, Brazil Fax: + $55113255-4145$ E-mail:marcoarap@hotmail.com 